\title{
Factors Affecting Temporal Variations of Cyanobacteria Composition and Microcystins in a Hypertrophic Urban Lake, Beijiing
}

\author{
Jiangqi Qu, Qingjing Zhang, Mo Zhang, Chengxia Jia, \\ Pan Liu, Mu Yang, Hua Zhu, Wentong Li \\ Department of Fisheries Ecology and Environmental, \\ Beijing Fisheries Research Institute, \\ Beijing, 100068, China
}

\begin{abstract}
At present, the occurrence of harmful algal bloom has become a serious environmental problem in China. A survey of the seasonal variations of algal bloom characteristics has been investigated in a shallow hypertrophic urban lake from June to October 2013 in this study. LC-MS results indicated that there are two main cyanobacteria toxins variants (MC-LR and MC-RR) during harmful algal blooms. The community structure of cyanobacteria showed that $81.04 \%$ of total cyanobacteria biomass belongs to Microcystis spp. and the average biomass of Microcystis spp. was $2.335 \mathrm{mg} \cdot \mathrm{L}^{-1}$. In addition, multivariate analyses by principal component and classifying analysis (PCCA) suggest that microcystins were mainly produced by Microcystis spp. and TP could promote MC production.
\end{abstract}

$\begin{array}{ccc}\text { Keywords- } & \text { microcystins; } & \text { temporal variations; } \\ \text { cyanobacteria blooms; factors } & & \end{array}$

\section{INTRODUCTION}

Urban lakes, as an integral component of urban ecosystems, have been heavily impacted by anthropogenic activities and urban expansion in China nowadays [1-2]. Especially in summer-autumn seasons, the fast growing phytoplankton has been response to the accelerated eutrophication processes and promotes the occurrence of algal blooms [3-5]. Blooms dominated by some cyanobacteria genera such as Microcystis spp., Oscillatoria spp., Anabaena spp. and Nostocs pp. could produce a group of hepatotoxins called microcystin (MC) [6-7]. Toxic blooms used for recreation are considered a serious urban environmental problem, which may reduce ecological and scenic values, biodiversity, and pose a threat to both of livestock and human health [8-9].

The dynamics of toxic blooms is a complex interaction between biological factors (e.g. microsystins content, cyanobacteria community, toxic species biomass) and environmental factors (e.g. temperature, nutrients, chlorophyll-a) [10-12]. Understanding when harmful algal blooms happened associated with biological factors and environmental factors are critical to effective urban lake management and reduce the health impact of toxin blooms. However, the toxicology and mechanism of algal blooms formation in urban lake are still poorly known in China [13]. In view of this, the purpose of the present study was to determine the temporal variability of cyanobacteria community structure and microcysins in Lake Taoranting, where is a famous recreation urban lake in Beijing. In addition, the possible mechanisms of harmful algal blooms regulated by biological and physio-chemical factors were also identified by multivariate analysis method.

\section{MATERIALS AND METHODS}

\section{A. Sampling and analysis}

Lake Taoranting $\left(39^{\circ} 87^{\prime} \mathrm{N}, 116^{\circ} 38^{\prime} \mathrm{E}\right)$ is located at the south western corner of Beijing's historic Xicheng District. In recent years, eutrophication and toxin blooms have been an intractable problem since 2000s. Cyanobacterial samples were collected from three sites during algal blooms (from June to October 2013). Water samples used for analysis were carried to laboratory immediately and measured by the standard method [14].

\section{B. Microcystins analysis}

Identification and quantification of $\mathrm{MC}$ were performed by LC/MS with Dionex Ultimate 3000 (Dionex, USA), an Ultimate XB- $\mathrm{C}_{18}$ column $(150 \mathrm{~mm} \times 4.6 \mathrm{~mm}, 5 \mu \mathrm{m})$ and a 3200Q TRAP LC/MS/MS Mass system (Aglient, USA). The mobile phase was Methanol (D) and water with $0.1 \%(\mathrm{v} / \mathrm{v})$ formic acid (A). The precursor ion $\mathrm{m} / \mathrm{z}$ of MC-LR, RR was 995.6 and 519.8, respectively.

\section{Statistical analysis}

PCCA and Spearman correlation matrix using Statistica 7.0 were performed to clear the relationship between MC concentrations, cyanbacterial community and environmental factors.

\section{RESULTS}

\section{A. Physio-chemical factors characteristics}

The physio-chemical factors characteristics during algal bloom from June to October 2013 in Lake Taoranting are listed in Table I. 
TABLE I. ENVIRONMENTAL PARAMETERS OF LAKE TAORANTING DURING ALGAL BLOOM

\begin{tabular}{ccccccccc}
\hline Date & $\mathrm{TN}$ & $\mathrm{TP}$ & $\mathrm{SAL}$ & TEMP & $\mathrm{pH}$ & $\mathrm{DO}$ & $\mathrm{NH}_{4}$ & $\begin{array}{c}\text { Chl- } \\
\mathrm{a}\end{array}$ \\
& $\mathrm{mg} / \mathrm{L}$ & $\mathrm{mg} / \mathrm{L}$ & & ${ }^{\circ} \mathrm{C}$ & & $\mathrm{mg} / \mathrm{L}$ & $\mathrm{mg} / \mathrm{L}$ & $\mathrm{mg} / \mathrm{L}$ \\
\hline $6 / 10$ & 3.2 & 0.12 & 0.26 & 25.3 & 9.89 & 11.7 & 2.5 & 41.5 \\
$6 / 20$ & 2.4 & 0.08 & 0.29 & 25.1 & 9.29 & 7.54 & 0.81 & 23.5 \\
$6 / 30$ & 2.8 & 0.1 & 0.275 & 25.2 & 9.59 & 9.62 & 0.2 & 32.5 \\
$7 / 10$ & 2.62 & 0.11 & 0.22 & 27.5 & 10.07 & 12.65 & 0.2 & 67.2 \\
$7 / 20$ & 1.31 & 0.06 & 0.29 & 27.7 & 9.15 & 7.87 & 2 & 50.2 \\
$7 / 30$ & 3.64 & 0.13 & 0.14 & 25 & 8.45 & 8.86 & 0.8 & 117 \\
$8 / 9$ & 4.05 & 0.19 & 0.21 & 28.6 & 9.72 & 17.82 & 1.3 & 123 \\
$8 / 19$ & 3.45 & 0.22 & 0.23 & 25.9 & 9.65 & 10.02 & 0.5 & 104 \\
$8 / 29$ & 4.8 & 0.23 & 0.25 & 26.3 & 9.21 & 10.1 & 1 & 87 \\
$9 / 8$ & 3.83 & 0.17 & 0.27 & 23.1 & 8.88 & 12.95 & 1.02 & 36.2 \\
$9 / 18$ & 3.71 & 0.15 & 0.28 & 21.8 & 7.89 & 6.99 & 0.2 & 43 \\
$9 / 28$ & 4.26 & 0.16 & 0.28 & 22.1 & 7.7 & 5.51 & 0.5 & 36 \\
$10 / 10$ & 3.5 & 0.08 & 0.28 & 18 & 9.01 & 9.4 & 0.3 & 16.1 \\
$10 / 21$ & 4.1 & 0.09 & 0.26 & 21.5 & 8.75 & 9.1 & 0.42 & 21.1 \\
\hline
\end{tabular}

\section{B. Variation of microsysitns concentration}

As shown in Fig.1, the seasonal variations of $\mathrm{MC}$ concentrations were detected in the surface water column during algal blooms. Two $\mathrm{MC}$ variants $(\mathrm{MC}-\mathrm{LR}$ and $\mathrm{MC}$ $-\mathrm{RR}$ ) were identified with a mean concentration of 0.895 $\pm 0.614 \mu \mathrm{g} \cdot \mathrm{L}^{-1}$ for MC-LR and $1.348 \pm 1.049 \mu \mathrm{g} \cdot \mathrm{L}^{-1}$ for MC-RR. A statically significant difference was observed between August and September for the average MC concentrations $(\mathrm{P}<0.05)$, and three peaks of $\mathrm{MC}$ concentrations were present during cyanobacteria blooms (Figure 1)

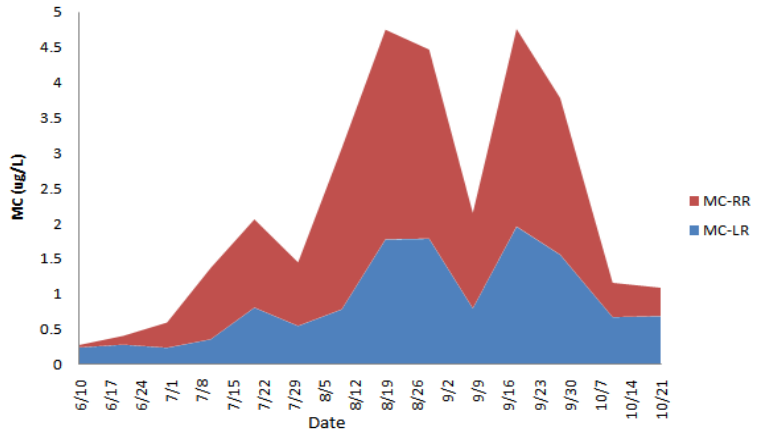

Figure 1. Variations of microcystins concentration in Lake Taoranting

\section{Cyanobacterial community dynamics}

The community structure of cyanobacteria in Lake Taoranting was observed during the study period. Cyanobacteria from the urban lake were comprised of 12 genera, 22 speices (Table II).The cyanobacterial community was dominated by Microcysis spp. throughout algal blooms. Temporal variations of the Microcysis spp. biomass were presented in Figure 2. The average biomass of Microcystis spp. was $2.335 \mathrm{mg} \cdot \mathrm{L}^{-1}$, accounting for $81.04 \%$ of the total biomass of cyanobacteria.
TABLE II. COMPOSITIONS OF CYANBACTERIA SPECIES IN LAKE TAORANTING

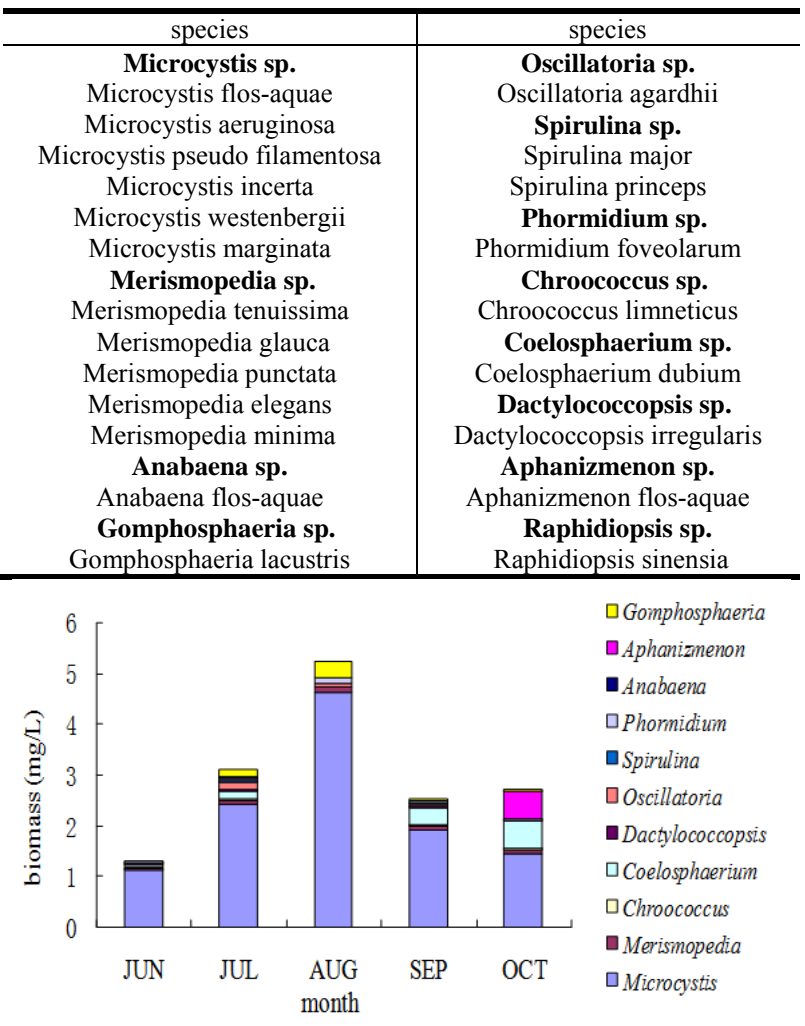

Figure 2. Temporal variations of cyanbacterial biomass in Lake Taoranting

\section{PCCA analysis}

In order to understand the complex dynamics process of algal blooms, the relationship between MC concentration and environmental factors were identified by PCCA analysis (Figure 3 ). With the PCCA, $63.41 \%$ of biological and environmental variation in the data was explained by Component Axis1 (23.59\%) and Component Axis $2(39.82 \%)$. Correlations with microcystins concentrations and factors variables are presented in Tab.3. PCCA results showed that MC (MC-LR and MC-RR) had high positive correlations with Microcysis spp. biomass $(\mathrm{P}<0.01)$ and Total phosphate concentrations $(\mathrm{P}<0.01)$.

TABLE III. CORRELATIONS BETWEEN MC AND ENVIRONMENTAL FACTORS IN LAKE TAORANTING

\begin{tabular}{llll}
\hline parameters & MC-LR & MC-RR & MC \\
\hline TN & $0.501^{*}$ & 0.448 & 0.477 \\
TP & $0.685^{*}$ & $0.808^{* *}$ & $0.779^{* *}$ \\
SAL & 0.095 & -0.120 & -0.041 \\
TEMP & -0.142 & 0.175 & 0.059 \\
pH & $-0.500^{*}$ & -0.283 & -0.371 \\
$\mathrm{NH}_{4}-\mathrm{N}$ & -0.236 & -0.175 & -0.202 \\
Chl-a & 0.246 & $0.533^{*}$ & 0.436 \\
COD & 0.215 & $0.141^{* *}$ & 0.172 \\
Micro & $0.827^{* *}$ & 0.860 & $0.866^{* *}$ \\
Cyano & $0.686^{*}$ & $0.856^{* *}$ & $0.810^{* *}$ \\
Oscill & 0.368 & $0.533^{*}$ & 0.482 \\
Phorm & 0.264 & $0.549^{*}$ & 0.453 \\
\hline
\end{tabular}




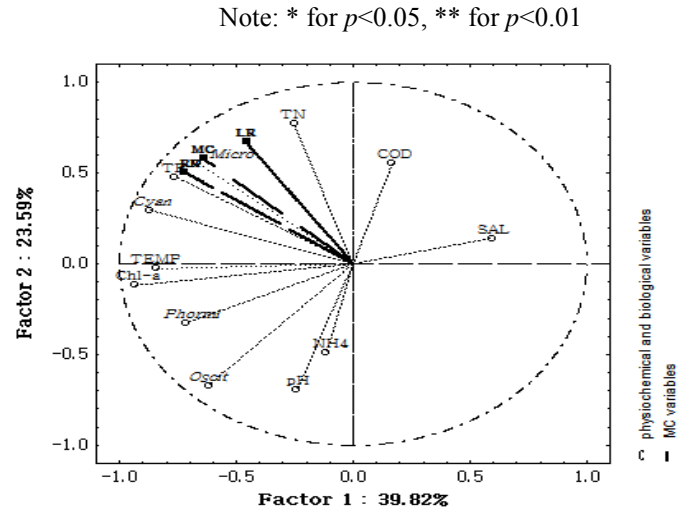

Figure 3. PCCA plot revealing relationship of physio-chemical or biological variables and MC variables in Lake Taoranting

\section{DISCUSSION}

Microsytins and eutrophication pollution are considered to become a severely water environment problem, especially in urban lakes [15].The water quality of Lake Taoranting can be classified as meso-eutrophic as the average of Chl-a concentrations was $57 \mathrm{mg} \cdot \mathrm{L}^{-1}$ in reference to OECD1982. Coinciding with eutrophication, a regular algal bloom had happened from June to October 2013. In general, the combine of higher temperature, sufficient light and increasing nutrients inputs during summer-autumn probably suitable cyanbacteria than the other phytoplankton [16-17]. Throughout the monitoring period, the bloom-forming populations were composed of some colonial and filamentous genera (Microcystis, Merismopedia, Anabaena, Gomphosphaeria, Oscillatoria, Spirulina, Phormidium, Chroococcus, Coelosphaerium, Dactylococcopsis, Aphanizmenon, Raphidiopsis) seem to follow a seasonal pattern in terms of cyanobacterial composition, abundance and densities (Figure 2).

PCCA was performed to explain the relationship between microsystins and biological and physio-chemical factors at a regional scale. A significant correlations between Microcystis biomass and microcystin concentration (especially MC-LR) $(p<0.01)$ suggest that Microcystis was the major microcystin-producing species in Lake Taoranting (Table III). Similar results were also reported in other regional hypereutrohic lakes in China [18-19]. Furthermore, the biomass of cyanobacteria (particular two species of Oscillatoria spp. and Phormidium spp.) were closely related to the production of MC-RR $(p<0.05)$, not correlated with MC-LR $(p>0.05)$, implicating that Oscillatoria agardhii and Phormidium foveolarum have ability to produce microcystin-RR. The results is not consistent with previously work that found that MC-RR mainly produced by Anabaena and Microcystis when a cyanobacteria blooms occurs in Yanghe reservoir, China [20].

During the whole study period, microcystin concentration was higher in August and September than the other months, and three peaks of MC concentrations were presented during cyanobacteria blooms. The PCCA results also showed that inorganic nutrients concentrations in the hypereutrophic Lake Taoranting are important factors regulating the variation of mirocystins production. Among the physio-chemical variables, TP was the key factors significantly associated with $\mathrm{MC}$ and MC-RR $(p<0.01)$, suggesting that phosphorus concentration play an important role in algal bloom formation and $\mathrm{MC}$ production. Previously works also found that TP concentration can promote the growth rates of both toxic and phytoplankton biomass [21].

\section{CONCLUSIONS}

In urban lakes, algal bloom is one of the most serious water pollution problems nowadays in China. The aim of our study is to understand the seasonal variations of cyanobacteria community and $\mathrm{MC}$ production and explore the mechanism of algal bloom-forming in a hypereutrohic urban lake. The present study results indicated that microcystins mainly produced by toxic species Microcystis sp. and TP was the key drivers which maybe regulate the dynamics of cyanobacterial composition and microcystins concentrations of the whole blooms. Our investigation suggested that further works should establish a long-term database to get comprehensive knowledge about cyanobacterial blooms, microcystins and nutrients management.

\section{ACKNOWLEDGEMENTS}

The research work was supported by Beijing Academy of Agriculture and Forestry Sciences Funds for Distinguished Young Scientists under Grant No. QNJJ201315; Chinese ministry of Science \&Technology support project (2012BAD25B03); Beijing agricultural Science \& technology innovation team (SCGWZJ20141103-3).

\section{REFERENCES}

[1] Hawkins, P.R., Chandrasena, N.R. \& Jones, G.J. E.A, Isolation and toxicity of Cylindrospermopsis raciborskii from an ornamental lake. Toxicon, 35, pp. 341-346, 1997.

[2] Jiang-qi Qu, Qing-jing Zhang \& Pan Liu. Spatiotemporal variation patterns of water quality of Taoranting Lake, Beijing of China. Chinese Journal of Applied Ecology, 24(4) , pp.1077-1084, 2013(In Chinese).

[3] Dai, R.H., Liu, H.J. \& Qu, J.H. Cyanobacteria and their toxins in Guanting Reservoir of Beijing, China. Journal of Hazardous Materials, 153(2008), pp. 470-477, 2007.

[4] Hai, X., Yang, L. \& Zhao, G. Anthropogenic impact on surface water quality in Taihu Lake region, China. Pedosphere ,19(6):765-78, 2009.

[5] Quiblier, C., Leboulanger, C., Sané, S. \& Dufour, P. Phytoplankton growth control and risk of cyanobacterial blooms in the lower Senegal River delta region. Water Researh, 42, pp.1023-34, 2008.

[6] Codd, G.A., Ward, C.J. \& Bell, S.G. Cyanobacterial toxins: occurrence, modes of action, health effects and exposure routes. Archives of Toxicology Supplement, 19, pp. 399-410, 1997.

[7] Carmichael, W.W. Cyanobacteria secondary metabolites - the cyanotoxins. Appl. Bacteriol,72, pp.445-459, 1992.

[8] Funari, E. \& Testai, E. Human health risk assessment related to cyanotoxins exposure.Crit. Rev. Toxicol.,38, pp.97-125, 2008. 
[9] Kardinaal, W.E.A., Janse, I. \& Agterveld, M.KV.A. Microcystis genotype succession in relation to microcystin concentrations in freshwater lakes. Aquatic Microbial Ecology, 48, pp.1-12, 2007.

[10] Jacoby, J.M., Collier, D.C., Welch, E.B. \& Hardy, F.J. Environmental factors associated with a toxic bloom of Microcystis aeruginosa. Can J Fish Aquat Sci, 57, pp.231-240, 2000.

[11] Wang, L., Cai, Q., Zhang, M., Xu, Y., Kong, L. \& Tan, L. Vertical distribution patterns of phytoplankton in summer Microcystis bloom period of Xiangxi Bay, Three Gorges Reservoir, China. Fresen Environ Bull , 20, pp.553-60, 2011 b.

[12] Wu, S.K., Xie, P \& Liang, G.D. Relationships between microcystins and environmental parameters in 30 subtropical shallow lakes along the Yangtze River, China. Freshwater Biology, 51(12), 2309-2319, 2006.

[13] Xiao-yi, Wang. Xiao-ping, Zhao. \& Zai-wen Liu. Comprehensive mechanism modeling on city lake cyanobacteria bloom formation. Acta Scientiae Circumstantiae, 32(7), 1677-1683, 2007.(in Chinese)

[14] Chen, W. M., Huang, X.F., \& Zhou, W. P., Lake Ecosystem observation, Beijing: Chinese Environmental and Scientific Press, 2005. (in Chinese)

[15] Chen. M., Chen. F., \& Xing.P. Microbial eukaryotic community in response to Microcystis spp. bloom, as assessed by an enclosure experiment in Lake Taihu, China . FEMS Microbiology Ecology, 74(1), 19-31, 2010

[16] Pitois. S., Jackson, M.H. \& Wood, B.J.B. Sources of the Eutrophication problems associated with toxic algae: An overview.Journal of Environmental Health, 64, pp. 25, 2001.

[17] Watson, S.B., McCauley, E. \& Downing, J.A. Patterns in phytoplankton taxonomic composition across temperate lakes of differing nutrient status. Limnology and Oceanography ,42 (3), 487-495, 1997.

[18] Wilhelm, S.W., Farnsley, S.E. \& LeCleir, G.R. The relationships between nutrients, cyanobacterial toxins and the microbial community in Taihu (Lake Tai), China. Harmful Algae, 10, pp.207-215, 2010.

[19] Da-ming, Li., Fan-xiang, Kong. \& Zhen, Yang .Studies on the abundance of toxic and non-toxic Microcystis population of Lake Chaohu in summer and winter. Acta Scientiae Circumstantiae, 31(12), pp. 2672-2680, 2011(in Chinese)

[20] Li, Z.L., Yu, J.W., \& Yang, M. Cyanobacterial population and harmful metabolites dynamics during a bloom in Yanghe Reservoir, North China. Harmful Algae, 9(5), pp. 481-488, 2010.

[21] Kotak, B.G, Lam, A.K.Y \& Prepas, E.E. Role of chemical and physical variables in regulating microcystin-LR concentration in phytoplankton of eutrophic lakes. Canadian Journal of Fisheries and Aquatic Sciences, 57, pp.1584-1593, 2000. 